\section{Empreendedorismo high-tech no Brasil: Condicionantes econômicos, políticos e culturais}

Sonia M. K. Guimarães

Lucas Rodrigues Azambuja ${ }^{1}$

Resumo: O artigo aborda o fenômeno do empreendedorismo tecnológico, em crescimento no Brasil, estimulado sobretudo pelo avanço das tecnologias de informação e comunicação e por ações governamentais como a Política de Desenvolvimento Produtivo, de maio de 2008, que propõe aumento de $10 \%$ no número de micro e pequenas exportadoras, até 2010 . O estudo baseia-se em uma abordagem multidimensional que destaca a importância de aspectos econômicos, institucionais, culturais e cognitivos e que supõe uma articulação entre fatores objetivos e subjetivos, entre níveis micro e macro. Os dados empíricos foram coletados através de entrevistas realizadas com empreendedores cujas empresas encontram-se em incubadoras tecnológicas, localizadas em três campi de universidades, no estado do Rio Grande do Sul. As evidências encontradas reforçam a hipótese de que estaria ocorrendo o que se poderia chamar de "mudança cultural", no sentido de que profissionais com alta qualificação, demandados pelo mercado de trabalho, apresentam comportamentos, valores e objetivos, distintos dos esperados - obter um emprego bem remunerado em uma grande empresa, pública ou privada; ênfase nos valores econômicos; individualismo; exercício de poder.

\section{Introdução}

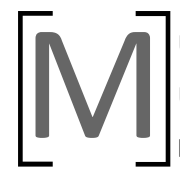

uito se tem debatido sobre as transformações econômicas do último quarto de século - globalização, inovações tecnológicas, reestruturação produtiva, intensificação da competitividade e rearranjos institucionais em níveis nacional e internacional. Tende-se a atribuir às mesmas implicações sociais negativas, interpretadas como decorrência de efeitos necessariamente perversos do capitalismo. 0 presente
Recebimento: 21.09.2009 Aprovado: 08.12.2009

1. Sonia M. K. Guimarães, professora titular do Departamento de Sociologia e PPG Sociologia, UFRGS, Pesquisadora 1B CNPq. Autora de vários artigos em periódicos indexados nacionais e internacionais (a maioria sob o sobrenome Larangeira), em especial sobre transformações no trabalho na área de serviços (bancos e telecom), reestruturação produtiva e sindicatos. PhD em sociologia pela London School of Economics and Political Science, Universidade de Londres. Realizou estágio pós-doutoral na Sloan School of Management, MIT, Cambridge (MA), Estados Unidos. Coordena o Grupo de Pesquisa/UFRGS/ CNPq Trabalho na Sociedade Contemporânea (http:// www.ufrgs.br/ ppgsocio). E-mail: sonia21@ufrgs.br. Lucas Rodrigues Azambuja é doutorando do Programa de PósGraduação de Sociologia da Universidade de São Paulo, bolsista do CNPq, mestre em sociologia e bacharel em ciências sociais pela UFRGS. É colaborador do Grupo de Pesquisa Trabalho na Sociedade Contemporânea. E-mail:

lucas.ra@terra.com.br. 
2. Cultura é aqui entendida como conjunto de valores e princípios mais ou menos estáveis, compartilhado por grupos sociais, estruturando um sistema de significados que orienta a definição de estratégias de ações também na vida econômica, delimitando as fronteiras do que é ou não racional. artigo reflete sobre a mesma realidade através de outro enfoque. Parte do pressuposto de que as mudanças que presenciamos $a$. provocam movimentos que não são unidirecionais, mas recíprocos; $b$. efetivam-se em nível objetivo mas, também, nos níveis cultural e cognitivo que se expressam na subjetividade dos atores; $c$. afetam os atores sociais que, por sua vez, não as recebem de forma passiva, mas atuam no sentido de proceder possíveis mudanças objetivas. Em resumo, considera-se que, no contexto de mudanças, os agentes sociais percebem alternativas e fazem escolhas (base para mudanças socioeconômicas mais amplas), ainda que sob limites de condicionantes objetivos, culturais e cognitivos.

O empreendedorismo tecnológico estimulado pelo avanço das tecnologias de informação e comunicação expressa a capacidade de responder aos desafios do contexto contemporâneo. Por essa razão, o tomamos como objeto de investigação e de reflexão. Argumenta-se que, possivelmente, uma mudança cultural $^{2}$ esteja ocorrendo entre os que trabalham no setor, no que se refere a valores e comportamentos, visto que se afastam dos que vigoraram no século passado, em especial, entre profissionais de nível superior, considerando-se a realidade brasileira. Para abordar a questão valemo-nos de uma abordagem multidimensional que atribui importância a aspectos econômicos, institucionais, culturais e cognitivos e que supõe uma articulação entre fatores objetivos e subjetivos, entre níveis micro e macro.

Constatações semelhantes as acima indicadas têm sido registradas pela literatura: Neff et alii (2005: 309) afirmam que a verdadeira novidade da "nova economia" seria a emergência de um segmento da força de trabalho com características "empreendedora", ou seja, disposta a enfrentar riscos e a aceitar maior grau de flexibilidade, tanto no emprego como na carreira, diferentemente do que ocorria com a força de trabalho do mundo industrial do passado, que buscava a estabilidade.

O estudo de Eesley (2008) - que examinou a situação de empreendedores high-tech na China - constatou que após as mudanças políticas (1999), o número daqueles empreendedores cresceu significativamente; dentre esses, a maioria $a$. havia deixado empregos em que atuaram por longo período; $b$. havia alcançado salários altos; $c$. provinha de famílias de baixa renda. Eesley conclui que, além dos efeitos das mudanças políticas, efeitos de mudanças culturais e psicológicas (legitimidade da condição de empreendedor) estariam atuando sobre aqueles indivíduos para que decidissem deixar os empregos tradicionais para se tornarem empreendedores. 
O estudo de Tremblay (2008) sobre o setor de multimídia em Montreal constata, sobre os profissionais do setor, que, dentre outras particularidades, a interação com o grupo de colegas, a troca de experiências e de conhecimentos seriam aspectos mais valorizados por eles do que recompensas propriamente econômicas. Dentre os critérios que definiriam "um bom lugar para trabalhar" aspectos como, desfrutar de autonomia, responsabilidade, intercâmbios, possibilidades de expressão, teriam prioridade sobre ganhos. O estudo de Tremblay chama a atenção para um aspecto significativo e que, de certa forma, também se evidenciou em nossa pesquisa: segundo a autora, estar-se-ia passando de uma perspectiva em que a informação e o conhecimento eram concebidos como fonte de poder individual para a concepção em que a informação e o conhecimento devem ser compartilhados e a competência ser coletiva.

Em estudo sobre o setor de software, Hualde e Micheli (2008) referem-se a outro aspecto relevante para a compreensão das mudanças atuais, ou seja, a convergência de avaliação tanto pela empresa como pelos empregados sobre as vantagens da flexibilidade: o pagamento por projeto, ainda que na categoria de remuneração eventual, é muitas vezes preferido pelos trabaIhadores do setor de software.

Constatações como esta acima alertam para a necessidade de cautela quando do exame de situações de trabalho flexível. Estudos sobre "trabalho atípico" tendem a ignorar elementos de ordem cultural e subjetiva, que levariam as pessoas a internalizar fatores como risco e incerteza, integrando-os aos seus projetos (Neff et alii, 2005: 310, passim). A flexibilidade das estruturas de emprego, seus riscos e incertezas podem ser percebidos como o custo a pagar pelo trabalho criativo e relativamente autônomo, altamente valorizado. Nesse sentido esteja possivelmente se afirmando, uma "nova ética do trabalho", o que poderia constituir-se em alerta às empresas no sentido de reorganização do trabalho, se quiserem reter profissionais hightech.

Estudos sobre a relação universidade-empresa, inovação e atividades de serviços intensivas em conhecimento evidenciam o crescimento do empreendedorismo high-tech também no Brasil. No que se refere à produção, desenvolvimento e/ou serviços relacionados a software ${ }^{3}$ - objeto de investigação que fundamenta este artigo - em 2008, o país contava com 8.500 empresas, ocupando a 12 a posição em nível mundial, movimentando US\$ 15 bilhões (quase 1\% do PIB brasileiro do mesmo ano), dos quais US\$ 5

3. O Programa Brasileiro da Qualidade e Produtividade em Software - PBQP Software - está inserido no Plano de Ação 2007-2010: Ciência, Tecnologia e Inovação para o Desenvolvimento Nacional, do governo federal, no qual o setor de software é considerado como um dos setores prioritários e estratégicos. 
bilhões correspondem à produção de softwares e US\$ 10 bilhões a serviços relacionados. Das empresas ocupadas com a produção e o desenvolvimento de softwares, $94 \%$ foram classificadas como micro e pequenas empresas (MPEs), representando cerca de $33 \%$ do total do mercado brasileiro de software. O crescimento anual dessas empresas tem sido de cerca de $10 \%$ (Associação Brasileira de Empresas de Software, www.abes.org.br, acesso em 04.08.2009).

A importância desse tipo de empresa no novo contexto de desenvolvimento brasileiro pode ser observada no destaque recebido na ação governamental Política de Desenvolvimento Produtivo, de maio de 2008, que propõe aumento de $10 \%$ no número de MPEs exportadoras, até 2010 . Impõese, portanto, um melhor conhecimento dessa realidade e do perfil do profissional que se dedica a esse tipo de negócio. $O$ interesse no tema aumenta, considerando-se que o referido empreendedor/empresário possui elevada qualificação técnica, em geral de nível superior, em alta demanda no mercado de trabalho no país e que, até então, tendia a optar pela a estabilidade de um emprego bem remunerado em grandes empresas.

Como explicar tal mudança? Que fatores são decisivos para configurar mudanças na ordem dos valores, interesses e objetivos de grupos econômico-

4. A falta de mão-deobra qualificada é um dos grandes obstáculos para expansão do setor de tecnologias da informação (TI) no Brasil. A estimativa é de que faltem entre 20 e 50 mil profissionais (Brasscom, 2008: 101; disponível no site http:// www.brasscom.org.br). Muitas empresas estão formando seus próprios profissionais. Segundo dados disponíveis no site da Brasscom, até 2012, estima-se que sejam criadas 100 mil vagas no setor.

5. Sobre o tema do empreendedorismo nas obras de Weber, cf. Swedberg (2004: 25-28). sociais: fatores de ordem objetiva (mudanças tecnológicas, globalização, liberalização dos mercados, crescimento e estabilidade econômica); ou, fatores de ordem cognitiva e cultural (atributos adquiridos através da educação e experiências anteriores, novas formas de interação); ou ambos? Que tipos de estímulos ou constrangimentos contribuem para $a$. incentivar ou inibir as escolhas dos agentes sociais no que concerne a novas maneiras de exercer atividades econômicas, em especial em relação ao empreendedorismo; $b$. como essa atividade é avaliada (alternativa digna e respeitada) por segmentos sociais com escolarização de nível superior? Correr riscos é considerado um valor para esses segmentos? Quem são os empreendedores/empresários, quais suas motivações para criar o negócio, especialmente no Brasil, onde o mercado de trabalho tem sido muito favorável aos profissionais desse tipo. ${ }^{4}$

No esforço de refletir sobre essas questões, buscou-se caracterizar o fenômeno do empreendedorismo - área de estudo consolidada na economia, na administração, na história econômica e na psicologia, mas pouco estudada na sociologia, particularmente, no Brasil, ainda que Max Weber ${ }^{5}$ seja uma referência sobre o tema. 
A relevância dessa área de estudos cresceu desde os anos 1980, em especial nos Estados Unidos e na Europa, por diferentes razões, entre as quais mudanças socioeconômicas que levaram à redução do emprego industrial e ao crescimento do desemprego; mudanças na ideologia político-econômica com a valorização da livre-iniciativa e do liberalismo, que se difundiu, inicialmente, com a chegada ao poder de Tatcher e Reagan e, após, com a queda da União Soviética; e, last but not least, devido ao crescimento das atividades intensivas em conhecimento e à relevância da inovação para o crescimento econômico, assim como a intensificação da competitividade que, por sua vez, diversificou e expandiu as cadeias produtivas favorecendo o surgimento de pequenas empresas, que floresceram nos anos 1990, sendo o Silicon Valley, na Califórnia, um dos exemplos significativos.

Para a elaboração deste estudo, foram realizadas 21 entrevistas semiestruturadas junto a empreendedores que produzem e desenvolvem softwares, em empresas inseridas em incubadoras tecnológicas, localizadas em três campi de universidades, no estado do Rio Grande do Sul.

As entrevistas foram realizadas no período de agosto de 2007 a junho de 2008; as questões propostas referiam-se à trajetória das empresas; motivações e objetivos dos empresários em sua decisão de criar uma empresa e instalá-la em uma incubadora; descrição do produto e grau de inovação pretendido; avaliação sobre as vantagens e desvantagens da incubadora; mecanismos de interação formais e informais com a universidade e com as demais empresas incubadas; caracterização da empresa e perfil dos empresários.

Com relação ao item "perfil dos empresários" - que inclui idade, cidade natal, formação acadêmica, histórico profissional e ocupação dos pais (ou exemplo empreendedor na família) - buscou-se também os dados referentes aos sócios (não entrevistados) de cada empresa. Sendo assim, a caracterização do perfil dos empresários contou com dados referentes ao respondente e aos seus sócios, totalizando 59 empresários. Depois de transcritas, as entrevistas foram analisadas com o auxílio do software NVivo.

O presente artigo divide-se em quatro partes: 1. apresentação de aspectos do contexto geral marcado pela importância do conhecimento e da inovação no desenvolvimento socioeconômico atual; 2 . apresentação de conceitos centrais destacando a dinâmica dos processos de mudança e desenvolvimento econômico-social e as interrelações entre a esfera macro dos con- 
dicionantes institucionais/materiais e a esfera micro dos condicionantes culturais/cognitivos; 3. relação de transformações político-econômico-culturais ocorridas no país com possíveis impactos no setor, destacando, assim, os condicionantes institucionais/materiais (esfera macro) que poderiam estar moldando a emergência do empreendedorismo high-tech, no caso brasileiro; 4. análise dos dados referentes aos empreendedores de incubadoras tecnológicas investigados, os quais revelam os condicionantes culturais/cognitivos situados na esfera micro. Ao final, propõem-se algumas considerações que apontem para temas e questões a serem examinadas mais detidamente em novos estudos.

\section{Conhecimento, tecnologia e desenvolvimento}

Já é um truísmo afirmar que, nas sociedades atuais, a capacidade de inovação define o grau de desenvolvimento sustentável e que o conhecimento é a fonte principal para o aumento da produtividade e a criação de riqueza, diferentemente do que ocorreu no passado quando a presença do capital físico era determinante.

A discussão sobre o que seja inovação - em especial no setor de serviços é vasta e controversa, sobretudo porque o esforço para a formulação do conceito de inovação baseia-se na realidade do setor industrial. A questão ganha novos contornos no contexto dos países em desenvolvimento, cuja realidade não pode ser comparada a dos países que estão na fronteira do conhecimento tecnológico. O Manual de Oslo, guia para a elaboração de pesquisas sobre inovação (OCDE, 2009), tenta minimizar o descompasso utilizando uma definição abrangente de inovação que inclui produtos, processos ou arranjos organizacionais, tecnologicamente novos ou substancialmente aprimorados, ou seja, desde atividades como cópia, imitação, adaptação, até atividades mais complexas envolvendo pesquisa (Figueiredo, 2006: 413).

Estudos sobre inovação - a partir dos anos 1980 - desfizeram a crença sobre a relação ciência-tecnologia-inovação, que supunha um caminho linear entre aquelas instâncias - do laboratório ao desenvolvimento tecnológico e daí para a inovação (produto no mercado). A nova abordagem ("sistema nacional de inovação", Lundvall, 2005), supõe a convergência entre produção científica e mercado e afirma que a mesma depende de um aparato institucional e político, bem como da mobilização de um conjunto de atores de diferentes áreas. 
Por outro lado, no novo contexto econômico e tecnológico, o setor de serviços adquire importância crescente com a expansão das atividades de serviços intensivos em conhecimento (Knowledge Intensive Business Services, Kibs - produção de softwares, implantação e administração de redes, processamento de dados, consultoria, entre tantos outros). Essas tecnologias, também chamadas "meta-tecnologias" (Finquelievich, 2007), atuam como indutores de inovação através de presença transversal em diferentes cadeias produtivas em todos os setores da economia. Alguns aspectos destacam-se em relação ao setor: $a$. tende a organizar-se na forma de rede, descentralizada, complexa e constantemente em mudança, demandando profissionais com conhecimentos de nível técnico-científico e espectro heterogêneo de habilidades e capacidades; $b$. a descentralização ocorre tanto no que se refere a empresas como a países, o que tem favorecido a emergência de empresas de alta tecnologia em países em desenvolvimento (Arora \& Gambardella, 2004; Eliasson 2006; Figueiredo, 2006); ${ }^{6}$ c. constitui-se de proporção expressiva de pequenas empresas, operando com margens estreitas de lucros e altos riscos; $d$. as relações de trabalho tendem a ser mais cooperativas e a supervisão de empregados, realizada de forma indireta, pelo mercado, ao contrário do tipo de supervisão direta, própria das grandes empresas do passado (Eliasson, 2006).

Nesse contexto, ganha importância, como já referido, a atividade "empreendedora". Segundo a OCDE, "empreendedor" seria o proprietário de um negócio que busca agregar valor, implementando novos produtos, processos ou mercados, contribuindo para a criação ou expansão da atividade econômica. A maioria dos países hoje - inclusive a China - tem incentivado a difusão e expansão do empreendedorismo através de políticas públicas. Independente das diferenças locais e/ou nacionais, distinção substantiva, refere-se aos que são empreendedores por ausência de alternativas ou por necessidade e os que o são pelo desejo de colocar em prática ideias inovadoras.

As tecnologias de informação e comunicação (TICs) constituem instrumento fundamental na relação inovação-empreendedorismo, favorecendo o acesso a dados e à informação, assim como a criação de redes que contribuem para a relação interfirmas, estimulando a emergência de micro e pequenas empresas bem sucedidas e muitas com capacidade de atuar globalmente - as chamadas "micro multinacionais" (Friedman, 2006: 461).

Neste processo de transformações, reordenam-se as relações entre empreendedorismo, conhecimento e tecnologia, desenvolvimento, mudan-
6. Tais mudanças permitem questionar a tese que afirma que, na nova divisão internacional, os países em desenvolvimento permaneceriam inevitavelmente como exportadores de commodities e suportes de uma industrialização baseada na dependência tecnológica (Katz, apud Figueiredo, 2006; Arora \& Gambardella, 2004; Ariffin \& Figueiredo, 2006). A atuação de países como Índia, China, Irlanda e Brasil (em menor escala), cuja capacidade tecnológica inovadora era, até bem pouco, inexpressiva, e que emergem como países com potencial inovador, ilustra a fragilidade daquela perspectiva. 
ças nas realidades políticas, econômicas e culturais que, por sua vez, favorecem a emergência de fenômenos específicos, por exemplo, o empreendedorismo high-tech. Trata-se, pois, de buscar as interrelações entre as forças presentes nestas realidades e que condicionam o modo de manifestação de fenômenos, como o que está sendo discutido neste artigo, nos diferentes contextos. A próxima seção aborda brevemente aspectos teóricoconceituais que parecem auxiliarem nesta busca.

\section{Considerações conceituais}

7. Schumpeter é considerado o principal formulador do conceito de empreendedor. Contudo, Swedberg (2000) chama a atenção para as diferentes concepções do autor sobre o fenômeno no decorrer do tempo. Afirma que a visão corrente que se tem da noção de Schumpeter de empreendedor, refere-se ao segundo capítulo da obra A teoria do desenvolvimento econômico, "The entrepreneur as innovation", em sua 2a edição em alemão, de 1926 (a 1a edição é de 1911 e a versão inglesa, de 1934).

8. Todavia, Schumpeter reconheceu posteriormente a importância do contexto social e histórico, relativizando o foco exclusivo no indivíduo (Aldrich, 2005: 454-455).

9. No original: "[...] different types of enterprises are likely to require different kind of entrepreneurs."
O tema "empreendedorismo" envolve uma intrincada discussão sobre o significado do termo. Para estudiosos baseados nos argumentos de Schumpeter, ${ }^{7}$ o termo empreendedor se aplicaria aos que desenvolvem atividades inovadoras e não se confundiria com proprietário de pequeno negócio tradicional. Destaca-se, assim, a dimensão subjetiva e aponta-se como uma das características centrais do empreendedorismo a capacidade de "reconhecer oportunidades" e de assumir riscos. ${ }^{8}$ Os críticos afirmam, entretanto, que "oportunidades" são fenômenos objetivos e como tal não estão ao alcance de todos. Nesse sentido, a dimensão objetiva se imporia (Aldrich, 2005).

A visão que destaca qualidades individuais peculiares tem tido pouca ou nenhuma influência nos estudos sociológicos. Por outro lado, a perspectiva que sublinha a importância do contexto econômico-social tende a reduzir o papel de fatores como os institucionais e/ou histórico-culturais, bem como o dos contextos espaciais, que podem tanto constranger como estimular a percepção de oportunidades e influenciar a ação dos agentes.

Parece incorreto adotar uma ou outra perspectiva de forma isolada. A proposta de uma análise multidimensional que considere um conjunto de fatores parece ser mais consistente (Thornton, 1999, passim), ainda que haja dificuldades em definir o ponto de interseção entre agência e as rápidas mudanças tecnológicas e mercadológicas em nível global. Além disso, "[...] é provável que diferentes tipos de empresas demandem diferentes tipos de empreendedores." 9

De fato, por se tratar de fenômeno universal, o empreendedorismo é, sobretudo, dinâmico; altera-se no tempo e no espaço em razão de transformações socioeconômicas e tecnológicas. Desta forma, fatores individuais ou socioculturais e organizacionais responsáveis pela emergência do fenômeno em um período, podem não sê-lo noutro, visto que a natureza dos 
empreendimentos e as qualidades e necessidades requeridas dos empreendedores também se modificam.

Para analisar o fenômeno do empreendedorismo tecnológico no Brasil atual, parte-se do pressuposto de que os atores sociais afetados por transformações socioeconômicas respondem às mesmas, buscando alternativas, perseguindo interesses e realizando escolhas, dentro de limites, por vezes estreitos, definidos por condicionantes institucionais, culturais e cognitivos. Considerando este pressuposto, as premissas da perspectiva neoinstitucionalista (Ingram \& Clay, 2000) parecem adequadas para analisar os fenômenos sociais, visto que considera não apenas os condicionantes materiais ou as predisposições subjetivas mas, também, a interrelação entre estes, assim como os fatores de ordem legal e cultural e suas influências recíprocas.

As instituições estabelecem regras que contribuem para reduzir incertezas e riscos advindos do conhecimento limitado dos agentes sociais. As instituições sociais, juntamente com as condições materiais e tecnológicas existentes, criam incentivos e/ou constrangimentos organizando a estrutura de oportunidades a partir da qual os agentes fazem suas escolhas (North, 2001; 2007; Denzau \& North, 1994). Porém, o modo como os indivíduos, os empreendedores e as organizações realizam suas escolhas e atuam, depende não apenas do aparato institucional, material e tecnológico (dimensão macro), mas ainda de fatores cognitivos como o nível de informação e conhecimentos adquiridos em experiências anteriores (dimensão micro). Portanto, a estrutura de cognição (tipos de informação e conhecimento, valores culturais, princípios morais e modelos mentais) condiciona o modo como os indivíduos interagem, submetem-se às regras, percebem e avaliam a estrutura de incentivos e oportunidades.

As escolhas e formas de organizações que os agentes assumem estão relacionadas aos recursos institucionais, às condições materiais e tecnológicas, bem como aos recursos de conhecimento. No caso em estudo, pode-se supor que a capacidade e decisão de empreender e inovar é moldada pelo conjunto de fatores institucionais/materiais e culturais/cognitivos.

Se a matriz institucional influencia a estrutura de condicionantes - formais e informais ${ }^{10}$-, de oportunidades e incentivos que define as escolhas dos agentes, os condicionantes culturais e cognitivos amoldam o modo como os mesmos realizam suas escolhas. Aqueles são produtos do processo de

10. Podem-se considerar como condicionantes institucionais formais constituições, leis, direitos de propriedade e contratos. Por outro lado, condicionantes institucionais informais são os costumes, os sistemas morais e os códigos de condutas socialmente compartilhados. Para essa distinção entre condicionantes formais e informais, cf. North (2007: 36-53). 
aprendizagem humana por meio do qual indivíduos ordenam e dão sentido à realidade ao seu redor e às informações e estímulos captados pelos sentidos (North, 2001; 2007; Denzau \& North, 1994).

No processo de aprendizagem, os agentes elaboram modelos mentais (recursos cognitivos a partir dos quais os indivíduos interpretam o mundo e agem sobre o mesmo) em decorrência de experiências particulares e propósitos imediatos, mas os modelos podem ser reelaborados para processar e interpretar outras informações e experiências - tal característica do processo de aprendizagem humana é denominada redescrição representacional ("representational redescription", North, 2001:251). Exemplo de redescrição representacional é a tentativa de reprodução internacional do modelo do Silicon Valley. Esse parece ser o caso da criação de micro e pequenas empresas de alta tecnologia, que se multiplicam ao redor do mundo em incubadoras e parques tecnológicos, em que se inclui o caso em estudo.

O exemplo acima é um caso típico de mudança de origem exógena, em que formas de produção de uma sociedade alteram a percepção de oportunidades de ganhos dos empreendedores e organizações de outras (North, 2001). Por outro lado, a competição seria, segundo North, o maior incentivo para aprender e vetor de mudanças endógenas à uma organização social e econômica:

11. No original: "[...] competition forces organizations to continually invest in skills and knowledge to survive. The kinds of skills and knowledge that individuals and their organizations acquire will shape evolving perceptions about opportunities and hence choices that will incrementally alter institutions."
[...] competição força as organizações a investirem continuamente em habilidades e conhecimentos para sobreviver. Os tipos de habilidades e conhecimento que indivíduos e suas organizações adquirem moldarão a evolução de percepções sobre as oportunidades e, deste modo, as escolhas que alterarão as instituições (North apud Ingram \& Clay, 2000: 540). ${ }^{11}$

As mudanças institucionais processam-se de maneira gradual, ubíqua e incremental, em razão das escolhas (rotineiras, através das normas e direitos existentes, ou, envolvendo alteração da matriz institucional existente) dos agentes econômicos, sociais e políticos (North, 2001; 2007). Alterações tendem a ocorrer em razão da expectativa de alcançar melhor desempenho com a modificação de uma ou mais das regulações institucionalmente estabelecidas. Exemplo desse processo é o debate que se desenvolve hoje no Brasil sobre a reestruturação da legislação trabalhista em razão de novas formas de contratação e de relação de emprego; ou, ainda, a redefinição de direitos de propriedade intelectual ou autoral em função das tecnologias 
de digitalização e distribuição de materiais de áudio e vídeo através de sites de compartilhamento de arquivos de áudio cujo percussor foi o Napster ${ }^{\circledR}$ ou os de vídeos como o YouTube ${ }^{\circledR}$.

Segundo a perspectiva neoinstitucionalista, há uma relação entre, de um lado, a aprendizagem e estrutura institucional de incentivos e constrangimentos e, de outro, as mudanças nas sociedades:

A velocidade da mudança econômica é função da taxa de aprendizagem, enquanto a direção da mudança é função das recompensas esperadas pelos diferentes tipos de conhecimentos adquiridos. Os modelos mentais que os atores desenvolvem moldam as percepções sobre as recompensas (North, 2001: 250). ${ }^{12}$

A seguir examinam-se condicionantes institucionais/materiais da esfera macro que estariam contribuindo para moldar a emergência do empreendedorismo tecnológico no Brasil. Na seção seguinte, destacam-se os condicionantes culturais/cognitivos relativos à dimensão micro, com base nos dados coletados através da pesquisa realizada entre empreendedores de incubadoras tecnológicas investigadas.

\section{A realidade brasileira:}

\section{Condicionantes materiais/institucionais}

Ao se considerar os novos padrões de desenvolvimento econômico que tem na inovação a base de sua sustentabilidade, a situação do Brasil apresenta um paradoxo preocupante. A participação de brasileiros na produção científica mundial passou de 0,44\%, em 1981, para 2,12 \%, em 2008, ocupando a 13a posição no ranking mundial, na frente de países como Suíça, Suécia e Rússia (posição afetada pela emigração de cientistas), próxima à posição da Coreia do Sul e Holanda ${ }^{13}$ (base de dados Thomson - Institute for Scientific Information, ISI, National Scientific Indicators, NSI, capturado em 07.05.2009 em http://www1.folha.uol.com.br/folha/ciencia; cf. também www.mct.gov.br). Todavia, o país não sustenta posição correspondente, tratando-se de índices relativos à inovação: em 2008, ocupava a 43a posição, atrás de países como Índia e África do Sul (The Global Information Technology

13. Entretanto, segundo a mesma fonte, o número de citações gerado pelas publicações de brasileiros continua abaixo da média mundial. Report 2008-2009. World Economic Fórum, capturado em 19.08.2009 http:// www.weforum.org/pdf/GCR08/GCR08.pdf). Em consequência, o país conta com um dos maiores parques industriais do mundo, mas produz principalmente produtos de baixo e médio valor agregado. 
14. Figueiredo (2006) adverte que tal avaliação deve ser considerada com cautela em razão de possíveis problemas metodológicos. De qualquer forma, mesmo corrigindo-se as possíveis distorções, a posição brasileira não deverá ficar muito acima do que a indicada.
15. A competição como incentivo à aprendizagem e habilidades e em consequência à mudança e ao desenvolvimento, conforme observa North (2001).
Constata-se, portanto, no Brasil, uma grande defasagem entre produção científica e inovação - grave problema no cenário atual.

O Brasil também se encontra em posição desvantajosa, comparado com 134 países, no que se refere à capacidade de utilizar oportunidades criadas pelas TICs para estimular o desenvolvimento e ampliar a competitividade da economia. Em 2008, ocupava as 59a posição, de acordo com The Global Information Technology Report 2008-2009 (World Economic Fórum). ${ }^{14}$

Observa-se baixo índice de graduados em ciências, matemática, computação e engenharias no país - cerca de 14\%, em 2007 -, bem como baixa qualidade do ensino de matemática: em 2006, o Brasil foi classificado em 54a posição dentre 57 países em testes realizado entre 400 mil alunos de 15 anos de idade (aproximadamente, 9.295 brasileiros) selecionados por amostragem estatística, segundo avaliação do Programme for International Student Assessment (apud Pinheiro \& Giambiagi, 2006: 267).

Os dados acima expressam o "perfil brasileiro" no que diz respeito ao modo de conceber e de produzir conhecimento que, de maneira geral, avalia negativamente a articulação entre campo científico e mercado. Esse perfil resultaria de uma matriz institucional construída a partir de ações do Estado e do meio acadêmico, conforme interpretação a seguir.

Os baixos índices de Pesquisa, Desenvolvimento e Inovação (PD\&I) que caracterizam a realidade brasileira, em especial o descompasso entre produção científica e inovação é, em grande parte, fruto de fatores econômicohistórico-culturais próprios de uma sociedade que se estruturou com base na grande propriedade, no sistema escravista e em relações sociais de caráter patrimonialista, bem conhecidas e que não cabe aqui detalhar. Tais características foram de certo modo reconstruídas no processo de industrialização, consolidado na segunda metade do século XX, sob os princípios do modelo de substituição de importações. Enquanto nos países asiáticos o foco do processo de industrialização era buscar competitividade internacional, o que impulsionou o processo de inovação, ${ }^{15}$ no Brasil, foi o desenvolvimento industrial direcionado para atender a demanda do mercado interno, sob proteção estatal (protecionismo tarifário, subsídios, controle de preços, reservas de mercado e incentivos fiscais e de crédito). Tal estratégia desestimulou a competição e a busca por maior produtividade e redução de custos; ao contrário, reproduziram-se protótipos obsoletos no exterior, sem que houvesse exigência de desenvolvimento de projetos de PD\&। 
para as empresas que aqui se instalaram. Ao deixar de promover a inovação, a política industrial contribuiu para desestimular a percepção daquela capacidade como um valor social e, em consequência, deixou de favorecer oportunidades para seu desenvolvimento. O déficit na balança comercial relativamente à indústria eletrônica e de informática, por exemplo, ilustra os resultados negativos daí decorrentes. Essa dificuldade verifica-se também no segmento de software: sendo este o segmento que mais cresce, mundialmente, na área de tecnologia de informação, tem baixíssima participação do Brasil no mercado mundial, diferentemente do que ocorre em outros países como Índia e Irlanda.

Por outro lado, a formação científica e de pesquisa acadêmica em nível nacional foram implantados apenas nos anos 1970, através de um sistema nacional de pós-graduação. $\mathrm{O}$ tipo de modelo então estabelecido relativamente ao financiamento público da pesquisa científica - completa autonomia face às demandas sociais - tem sido questionado, mundialmente, visto que o empenho da sociedade para sustentar o sistema de C\&T, no caso de países como o Brasil, apresenta baixa repercussão no que se refere à inovação.

O debate sobre como melhor capitalizar o crescente esforço de investimento em C\&T realizado pelas sociedades contemporâneas tem sido cada vez mais orientado pela tendência de avaliar a direção e os resultados do conhecimento científico-tecnológico produzido, considerando-se que o mesmo deva contribuir para a produção de riqueza econômico-social (Salerno, 2004). Insere-se, aqui, a questão controversa sobre o papel da universidade e da ciência na promoção do bem-estar social.

A relação entre $C \& T$ e desenvolvimento econômico e social vem-se alterando: de uma abordagem que priorizava a criação de infraestrutura necessária ao crescimento econômico, e que concebia a transferência de conhecimento como sendo automática, passa-se a formas orientadas de transmissão de conhecimentos e de transferência de tecnologias, de avaliação dos resultados da pesquisa, no sentido de estimular a utilização mais objetiva dos mesmos, visando à convergência entre produção científica e política industrial, com o objetivo de ampliar a capacidade competitiva sustentável das empresas (Vedovello et alii, 2001).

A matriz institucional - exposta acima em seus contornos mais gerais configura uma estrutura de incentivos e constrangimentos que, ao longo do último quarto de século, sofre profundas transformações, modelando 
uma nova estrutura de incentivos e constrangimentos institucionais que, possivelmente, esteja contribuindo para estimular a emergência do empreendedorismo tecnológico.

De que forma, Estado, instituição acadêmica, mercado e agentes sociais envolvidos têm, no Brasil, respondido aos desafios da sociedade do conhecimento?

Na política, a democracia vem-se consolidando desde meados dos anos 1980, apesar de percalços institucionais como o funcionamento da vida político-partidária. Na economia, observou-se o rompimento de alguns veIhos paradigmas, como o domínio da grande empresa estatal, financiada pela inflação e o excessivo protecionismo. O direcionamento das políticas macroeconômicas voltou-se para o controle da inflação, reduzindo em parte a incerteza e permitindo o crescimento econômico, ainda que persistam obstáculos que impedem um crescimento econômico mais significativo. Mesmo assim, registram-se elevação dos indicadores sociais em áreas como educação, saúde, saneamento básico, proteção social, renda familiar e consumo de bens duráveis, embora ainda distantes dos níveis desejáveis. A perspectiva paternalista e clientelista vem sendo gradativamente substituída por noções de descentralização, eficiência e avaliação do desempenho.

A privatização de empresas e a liberalização dos mercados, em alguns setores, contribuíram positivamente - apesar de opiniões em contrário - como no caso das telecomunicações, cuja expansão significativa e o aumento da competição, particularmente na telefonia móvel, difundiram o acesso desse bem, hoje, indispensável, também aos segmentos sociais de baixa renda.

O nível educacional da população brasileira tem-se elevado desde os anos 1980, em especial, na década de 1990, quando se verificou o aumento de matrícula nos três níveis de escolaridade (fundamental, médio e superior) e o aumento da média de anos de estudo da população em idade ativa (PIA), que em 1992 era de 4,87 anos e, em 2007, passou para 6,92 anos (Ministério de Ciência e Tecnologia, 2009), contribuindo para o aumento da produtividade do trabalho.

Em suma, em âmbito macro, observam-se mudanças qualitativas tanto nos condicionantes políticos, quanto nos econômicos e sociais, no que se refere à matriz institucional da sociedade brasileira. 
Desde meados dos anos 1980 (em 1985, foi criado o Ministério de Ciência e Tecnologia), o país visa a implementar políticas que favoreçam a mudança de paradigma para que possa atingir um novo patamar de produção baseado na inovação, capaz de competir no comércio internacional de forma qualificada e que reverta as condições que conduziram o processo de industrialização brasileira, cujo desenvolvimento não favoreceu a emergência de iniciativas inovadoras.

No final dos anos 1980, implementam-se políticas de incentivo fiscal para desenvolvimento de P\&D em empresas e, em abril de 1990, foi lançada a Política Industrial e de Comércio Exterior (Pice) constituída de vários programas que buscavam, através de incentivos fiscais e créditos, estimular o desenvolvimento da capacidade tecnológica do país. Em outubro de 1991, foi aprovada a Lei n. 8.248/91, também designada como "Lei de Informática" (regulamentada em 1993) visando a estimular o desenvolvimento do setor de TICs no Brasil (Figueiredo, 2006), sob regime de competição industrial através de incentivos fiscais voltados à implementação de atividades de P\&D em empresas do setor (MCT, 2009).

Ao final dos anos 1990, foi instituída a política dos fundos setoriais de ciência e tecnologia, constituindo-se em instrumento fundamental de apoio ao desenvolvimento da CT\&l, através da disponibilidade de recursos financeiros ampliados com taxas de juros subsidiadas para o desenvolvimento da pesquisa nos setores público e privado, incluindo o fomento à parceria universidade/instituições de pesquisa e o setor produtivo, destacando-se o apoio à inovação nas micro e pequenas empresas, bem como à criação de incubadoras e parques tecnológicos.

Em maio de 2000, foi criado o Projeto Inovar com o objetivo de financiar pesquisadores que atuem em empresas de base tecnológica, através do Programa de Apoio à Pesquisa em Empresas (Pappe).

Em novembro de 2003, foi lançado o documento "Diretrizes de política industrial, tecnológica e de comércio exterior" (PITCE) baseado na concepção de integração do sistema produtivo com inovação tecnológica e competitividade no mercado exterior, destacando como linhas de ação: 1. a inovação e o desenvolvimento tecnológico; 2 . a inserção externa; 3 . a modernização industrial e, definindo como áreas estratégicas as de $a$. semicondutores; $b$. softwares; $c$. bens de capital; $d$. fármacos e medicamentos. Em dezembro de 2004, foi promulgada a Lei de Inovação, visando a favorecer a coopera- 
ção entre universidades, institutos de pesquisa e empresas (Salerno, 2004). A Lei de Inovação refere-se explicitamente ao apoio a "ações de empreendedorismo tecnológico", ao mesmo tempo em que altera a base jurídica, liberando as instituições de C\&T para realizar contratos remunerados com empresas incubadas, para uso de seus laboratórios (Morais, 2008).

A Lei n. 11.196, de 21.11.2005, a chamada Lei do Bem, institui incentivo fiscal às empresas que desenvolvam pesquisa tecnológica e contratem pesquisadores. $\mathrm{O}$ objetivo, entre outros, é o de incentivar a transferência de conhecimento científico e/ou tecnológico visando ao desenvolvimento de capacidade tecnológica inovadora nas empresas, tendo em vista a inserção tecnologicamente qualificada do Brasil no mercado internacional.

Outros programas e mecanismos de crédito e subvenções têm sido criados recentemente, a exemplo da capitalização de fundos de investimento (venture capital, capital semente) em empresas inovadoras.

Em maio de 2008, foi instituída a política de desenvolvimento produtivo que privilegia áreas estratégicas que incluem as TICs, a nanotecnologia, a biotecnologia, a energia nuclear, entre outras. No que se refere às tecnologias de informação e comunicação, o objetivo é posicionar o Brasil como produtor e exportador relevante de softwares e serviços de TI (http:// www.desenvolvimento.gov.br/pdp/arquivos/destswf1224095287. ppt\#461,1, Inovar e investir para sustentar o crescimento, capturado em 17.08.2009).

As políticas acima referidas ampliaram significativamente os mecanismos de financiamento e subvenções com uma série de programas e iniciativas de apoio a diferentes fases da cadeia produtiva visando a estimular o desenvolvimento de produtos e processos inovadores.

Configura-se, portanto, um conjunto de incentivos diretos, por parte do Estado, estimulando a emergência da atividade empreendedora articulada com o conhecimento científico e tecnológico.

Os parques e incubadoras tecnológicos abrigados ou não em universidades têm o papel de suporte para empresas que buscam desenvolver bens e serviços que incorporem tecnologias avançadas, tendo em vista afirmar-se no mercado. Em 2008, o Brasil possuía 74 parques tecnológicos localizados nas diferentes regiões do país, abrigando cerca de 520 empresas, com re- 
ceita aproximada de $R \$ 1,68$ bilhão, volume de exportação estimado em $R$ \$ 116 milhões e geração de cerca de 26.233 postos de trabalho, com concentração de profissionais de nível superior e pós-graduação (Valor Econômico, seção "Empresas", 17.12.2008).

As iniciativas acima referidas visando a estimular a criação de empresas inovadoras constituem, juntamente com as mudanças macroscópicas na economia e na política nacional, uma ampliação da estrutura de oportunidades que contribui para condicionar as escolhas dos agentes sociais, como se verá adiante.

A seguir, examinam-se, com base nos dados da pesquisa entre empreendedores de incubadoras tecnológicas, os condicionantes culturais/cognitivos situados na esfera micro.

\section{Empresas de alta tecnologia incubadas}

As incubadoras tecnológicas podem ser consideradas ambientes institucionais intermediários, pois oferecem uma estrutura de condicionantes cristalizada nas regras do processo de incubação. Tal como a matriz institucional macroscópica que interage com os condicionantes culturais/cognitivos de nível micro, a organização da incubação também interage com estes últimos. Portanto, cabe citar alguns condicionantes formais e informais contidos no processo de incubação sem, todavia, entrar nos detalhes deste último, visto não constituir o foco desse artigo.

As empresas pesquisadas são micro empresas, com número reduzido de empregados (às vezes, nenhum), envolvidas com produtos e serviços considerados inovações tecnológicas, voltadas para a produção e desenvolvimento de software. A admissão da empresa em incubadoras depende de processo seletivo. No caso das incubadoras estudadas, em especial em duas delas, a seleção é bastante disputada: os candidatos à incubação devem submeter um projeto para desenvolvimento do produto ou serviço com duração de dois anos, cuja viabilidade é julgada de forma criteriosa pelos gestores das incubadoras. Portanto, o primeiro obstáculo a vencer é o ingresso nas incubadoras. Durante o período de incubação, as empresas são permanentemente avaliadas pelas gerências quanto ao desempenho e cumprimento dos objetivos propostos. As incubadoras têm um papel relevante no desenvolvimento dos condicionantes culturais/cognitivos dos empreendedores, uma vez que interferem na experiência destes últimos. 
Ao mesmo tempo em que as incubadoras modelam e constrangem a experiência dos empreendedores impondo-lhes metas, prazos e regras, também oferecem uma estrutura de incentivos formais e informais. Quanto à estrutura de incentivos formais, encontram-se benefícios advindos do contrato de incubação, entre outros: dispor de infraestrutura para o desenvolvimento do negócio a baixo custo (espaço, telefone, fax, sala de reuniões), de assessoria e suporte gerencial, comercial (habilidade que os empresários em formação geralmente desconhecem) e para obtenção de financiamentos; contar com oportunidades de participação em feiras nacionais e internacionais especializadas; desfrutar de visibilidade e credibilidade (crucial para empresas nascentes) por estarem ligadas a universidades conceituadas.

Ainda em relação ao grupo de incentivos formais, encontra-se a ação das incubadoras na obtenção de financiamentos de órgãos governamentais como, Finep, CNPq e BNDES, fator estratégico de incentivo e apoio à atividade empreendedora de alta tecnologia, ao mesmo tempo em que atuam, durante o período de incubação, como mecanismo de controle e de monitoramento para avaliação do desempenho da empresa. Dessa forma, empreender em incubadora tecnológica tende a reduzir o risco e a favorecer o êxito do negócio, oferecendo maior segurança ao empreendedor, o que nem sempre ocorre com empreendimentos que se estabelecem, individualmente, sem esse tipo de apoio. Simultaneamente, o processo de incubação constrange, isto é, modela a experiência empreendedora estabelecendo regras, prazos e metas.

Quanto aos incentivos informais, os empresários mencionam os benefícios decorrentes do fato de pertencerem à rede de profissionais da área, constituída pelos demais empresários incubados no local, cuja norma de comportamento tende a valorizar a cooperação e a reciprocidade, através de troca de informações técnicas e/ou de mercado consideradas valiosas. Ainda em nível informal, os empresários apontam como relevante a proximidade da universidade, o que facilitaria o acesso a recursos e/ou suportes técnico-científicos disponíveis em laboratórios ou grupos de pesquisa, em especial o contato com alunos integrantes de tais grupos. Da mesma forma, os empresários afirmam valorizar as interações e informações a que julgam ter acesso por estarem localizados em espaço contíguo a parques tecnológicos que contam com a presença de conhecidas empresas multinacionais. Frente aos condicionantes advindos tanto das incubadoras como da matriz macro institucional, quais são as expectativas e objetivos dos empreendedores? Durante o período de incubação, os desafios enfrentados pelas empresas 
não são poucos: desenvolver inovações tecnológicas para o mercado requer esforço e pertinácia, não apenas no trabalho de pesquisa, mas também, no gerenciamento do negócio. Ainda que o tipo de produção não exija grandes investimentos, o período de incubação, em geral, significa carência de recursos (a maioria dos entrevistados não têm financiamento, exceto auxílio familiar), o que significa, na maior parte das vezes, privações pessoais ou trabalho complementar para garantir a sobrevivência.

Apesar das grandes dificuldades, observou-se notável disposição e otimismo entre os entrevistados para prosseguir na tentativa de alcançar êxito em suas iniciativas de inovar tecnologicamente. A motivação que os move, entretanto, não é gerada apenas por objetivos de ganhos econômicos; o principal fator mencionado é o de trabalhar em ambiente desafiador, desejo de "realização pessoal". Os entrevistados afirmaram preferir os riscos e incertezas, a usufruir estabilidade e segurança em ambiente de trabalho sem estímulos criativos. Considere-se que, no caso estudado, a escolha pelo ambiente de trabalho desafiador em troca da estabilidade no emprego e boa remuneração, não é um subterfúgio para justificar dificuldades no mercado de trabalho. Conforme já indicado (cf. nota 4), há carência no mercado de trabalho brasileiro de profissionais com as qualificações dos entrevistados.

A disposição de trocar a estabilidade de um "bom" emprego pelo risco e incerteza, em razão, sobretudo, do desejo de fugir da rotina e de perseguir desafios intelectuais, pode ser interpretada como uma mudança no comportamento e nos valores de profissionais de nível superior que desfrutam de boa aceitação no mercado de trabalho.

Quem são esses profissionais? Ao responder essa questão, são evidenciados alguns aspectos das experiências anteriores dos respondentes que podem elucidar a formação tanto das expectativas mencionadas como dos modelos mentais, das estratégias que esses empreendedores estão desenvolvendo, como veremos em seguida.

Ao se considerar não apenas os entrevistados, mas também os sócios (total: 59 empresários), mais da metade (31 empresários) é constituída por pessoas com idade entre 23 a 31 anos; sendo que cerca de $70 \%$ do total (42 empresários) têm menos de 40 anos. São, portanto, na grande maioria, jovens. Todos os 59 empreendedores (entrevistados e sócios), exceto três, possuem formação de nível superior (a maioria com formação em engenharia, informática e administração), sendo que um terço deles com cursos de 
pós-graduação concluídos ou em andamento (mestrado, doutorado e especialização). Número expressivo deles (31 dos 59) teve, durante o período de graduação ou pós-graduação, experiência de participação em pesquisa acadêmica, sendo que alguns desenvolvem produtos ou serviços iniciados durante aquele período.

Quanto à origem social, ao contrário do que se tende a acreditar, a maioria dos entrevistados e de seus sócios provém de famílias sem experiência empresarial (32 dos respondentes, entre 47; 12, não responderam). Dos 32, 25 indicaram que os pais foram ou são funcionários públicos ou assalariados do setor privado. Os entrevistados e seus sócios provêm de famílias de classe média, com valores centrados na educação, no trabalho e na capacidade de realização.

Número expressivo dos entrevistados e de seus sócios já foi empregado assalariado em empresas de alta tecnologia. Destacam dessa experiência aspectos positivos como o conhecimento adquirido, o desenvolvimento de habilidades, assim como a capacidade e o desejo de oferecer produto ou serviço mais aperfeiçoado. Em alguns casos, o antigo emprego propiciou condições para a formação da sociedade empresarial.

A maior parte dos entrevistados foi integrante de grupos de pesquisa na universidade, o que se constituiu, segundo seus relatos, em possibilidade de visualizar oportunidades tanto no que se refere à produção de inovação, como a formação de parceria com colegas para a criação da empresa.

As experiências anteriores tanto em empresas como empregados e/ou como integrantes de grupos de pesquisa acadêmicas foram consideradas relevantes pelos entrevistados para a decisão de tornarem-se empresários.

A presença de mulheres nas empresas investigadas é praticamente nula. Foi encontrada apenas uma profissional realizando doutorado em informática e decidida a prosseguir na carreira acadêmica; na empresa, apenas auxiliava o marido.

Os entrevistados veem o futuro de suas empresas com otimismo: julgam que têm possibilidades de obter sucesso, mesmo fora da incubadora (as entrevistas foram realizadas durante período de crescimento econômico no país), embora a quase totalidade tenha manifestado desejo de permanecer nos parques tecnológicos após graduarem-se (no caso de existência 
dos mesmos), para desfrutar da proximidade do ambiente estimulante de pesquisa e inovação, onde o recrutamento de pessoal qualificado e informações técnicas estariam mais facilmente acessíveis.

Por fim, quais são as estratégias e práticas que os empreendedores incubados desenvolvem como resultado tanto dos condicionantes institucionais como dos culturais/cognitivos?

Primeiro, observa-se uma ação voltada para o trabalho árduo e competitivo, que se reflete na dedicação à empresa, que abrange muitas horas do dia; todos declaram trabalhar mais de oito horas; alguns declararam trabalhar "o dia inteiro", inclusive de madrugada, visto que além das horas na empresa, levam trabalho para casa; alguns afirmam a necessidade de trabalhar, de vez em quando, durante os finais de semana. Entretanto, não há manifestação de insatisfação com o número de horas trabalhadas; alguns vêem vantagem no fato de desfrutarem o que chamam "grau de liberdade" - podem escolher como distribuir o trabalho. Cabe reproduzir alguns depoimentos:

- Passo por vários apertos (questão financeira) [...] mas estou dez vezes mais feliz do que se estivesse em qualquer outro lugar (empresário entrevistado em 2007).

- Sempre tive ideias demais para ficar dentro de um escritório [...]. [No emprego] não conseguia levar minhas ideias adiante [...] (empresário entrevistado em 2007).

- Não me vejo num emprego, concursado, ganhando bem, com estabilidade; acho que não ia me sentir bem (empresário entrevistado em 2007).

Segundo, subjazem, entre os empreendedores, modelos mentais que favorecem o desenvolvimento de relações de trabalho horizontais, ou seja, relações com empregados, a maioria estagiários, abertas e pautadas pela cooperação. Vale reproduzir um depoimento ilustrativo do espírito que vigora naquele contexto:

- Eles percebem que nada é fácil... eles crescem junto conosco... o meu estagiário vai fazer o trabalho de conclusão... ele fala: "tive a ideia de desenvolver um robô..." Eu digo: Beleza! O que precisas? Nós vamos apoiá-lo; ele vai se sentir motivado... fazemos sessões de brain storm: estamos com problema, todo mundo vai ajudar a resolver... pode ser desde pendurar a 
cortina... as ideias surgem... projetos inovadores não faltam... Os estagiários são tão envolvidos com nossos produtos que eles acabam sugerindo... quem sabe faço trabalho sobre isso; posso ajudar nisso... Trazem a universidade e o conhecimento para aqui (empresário entrevistado em 2008).

Esta é também uma estratégia para reter recursos humanos qualificados e disputados no mercado de trabalho, para competir com as grandes empresas: os empreendedores oferecem aos empregados ambiente de trabalho atraente - horário flexível, trabalho criativo e desafiador e relativa autonomia.

Por fim, estratégias voltadas para busca da inovação e do conhecimento através da interação das empresas com a universidade nem sempre ocorrem em termos propriamente técnico-científicos ou formais; entretanto, a proximidade e a possibilidade existente de apoio da universidade é valorizada pelos empresários, por acreditarem que suas atividades dependem do contínuo desenvolvimento da pesquisa acadêmica. Os entrevistados valorizam sobremaneira a pesquisa e a inovação e estão imbuídos de que seu trabalho deve pautar-se por tais valores.

Figueiredo (2006) estudando a relação entre institutos tecnológicos e universidades chegou a resultados semelhantes. Evidencia-se a importância do meio/espaço social característico à universidade, como ambiente estimulante à inovação, o que reforça a perspectiva de que esta depende daquele. Os entrevistados afirmam, entretanto, que o ritmo da universidade é mais lento do que o exigido pela empresa: a contribuição da universidade em termos de conhecimento seria, sobretudo, de longo prazo.

\section{Conclusões}

As constatações extraídas do estudo sobre empreendedorismo em atividades intensivas em conhecimento oferecem subsídios à hipótese de que estaria ocorrendo o que se poderia chamar uma "mudança cultural", no sentido de que profissionais com alta qualificação, demandados pelo mercado de trabalho, apresentam comportamentos, valores e objetivos, distintos dos esperados - obtenção de um emprego bem remunerado em uma grande empresa, pública ou privada; ênfase nos valores econômicos; individualismo; exercício de poder.

O que explicaria a mudança de comportamento dos empreendedores entrevistados em relação a profissionais que poderiam ter seguido o mesmo caminho no passado? 
A razão da mudança não está clara. Vários fatores poderiam ser mencionados, entretanto, alguns parecem destacar-se: $a$. mudanças no paradigma econômico, ocorrido nas últimas décadas que levaram a transformações como a desverticalização das empresas e, em especial, o crescimento da demanda por serviços intensivos em conhecimento, assim como o baixo custo de investimento inicial necessário para a criação de empresas, em razão da centralidade das TICs para o desenvolvimento da inovação; $b$. novo quadro institucional, no Brasil, com forte apoio governamental ao empreendedorismo tecnológico inovador, através de incentivos formais para o financiamento de incubadoras tecnológicas e mediante estímulos para uma relação mais próxima entre universidade e empresa. Todos os respondentes manifestaram-se positivamente em relação ao apoio da incubadora ao empreendimento; c. a experiência anterior dos empreendedores tanto como alunos de graduação e/ou de pós-graduação e o envolvimento com a pesquisa acadêmica, quanto como a experiência de assalariado em empresas de alta tecnologia.

A socialização como pesquisador possivelmente tenha estimulado o gosto pela pesquisa e a capacidade inovadora, contribuindo para tornar a busca por um trabalho criativo mais importante do que a estabilidade "morna", sem desafio intelectual. A experiência como empregado permitiu o conhecimento sobre o produto e/ou sobre o mercado, assim como o desenvolvimento de habilidades e o desejo de produzir um produto ou serviço mais aperfeiçoado. O emprego serviu também como meio de estabelecer relações com outros profissionais com o mesmo perfil; em alguns casos, daí surgiu a ideia de formar uma sociedade e criar uma empresa.

Evidencia-se, portanto, de um lado, a importância de fatores como a presença das novas tecnologias, da crescente demanda por serviços intensivos em conhecimento e os incentivos governamentais, parte das condições macroeconômicas, dos marcos legais que regulam a atividade de negócio e os recursos tecnológicos e financeiros disponíveis, refletindo os condicionantes materiais e institucionais que definem a estrutura de oportunidades para o desenvolvimento do empreendedorismo high-tech. Ainda no que se refere aos condicionantes materiais, a maior estabilidade macroeconômica permite maior previsibilidade e tende a produzir impacto positivo sobre as condições para empreender. Ao mesmo tempo, a política governamental favorece e estimula jovens universitários a iniciar um empreendimento independente ou manter seu empreendimento como uma trajetória ocupacional efetiva. 
De outro lado, as trajetórias dos atores revelam a influência de condicionantes culturais e cognitivos: os tipos de estratégias, organizações e práticas desenvolvidas pelos agentes podem ser considerados como resultantes de recursos culturais e cognitivos incorporados através de suas experiências anteriores.

A combinação dos fatores acima referidos permite compreender a forma como opera a interrelação entre os condicionantes, em níveis micro e macro, que teriam favorecido a emergência do fenômeno em estudo.

Outro aspecto a destacar é a importância do meio/espaço social que se expressa através da interação entre as empresas incubadas que se realiza tanto em nível formal, através de reuniões periódicas organizadas pela incubadora, quanto informal através de encontros ocasionais cotidianos (no almoço, no cafezinho, em eventos promovidos pelas universidades), através de troca de informações, do acesso a redes - pessoas que seriam referências e que poderiam auxiliar em um ou outro aspecto do negócio. A interação entre as empresas é considerada valiosa pelos entrevistados, não apenas pela troca de experiências, mas também, por propiciarem atividades conjuntas como pedidos de financiamento. Dado que as empresas não são concorrentes, a interação entre as mesmas pode realizar-se de forma mais aberta e ao se encontrarem em situação de construção do negócio e de incertezas, desenvolvem certo clima solidário de ajuda mútua, uma identidade coletiva. Os empresários entrevistados experimentam a configuração que se aproximaria do que alguns identificaram como cluster - empresas que atuam não isoladamente, mas na forma de rede, em que interagem com o território, com outras empresas e com outros agentes que podem estar representando o poder público, associações da sociedade civil, formando uma coletividade (Artopoulos \& Méndez, 2007: 21). Essas formas de interação regulares e cotidianas produzem regras informais que regulam e modelam as ações entre os membros do grupo de empreendedores.

Nesse ambiente, prevaleceria uma lógica da cooperação - que inclui também os compradores -, apontada por Castells como característica da nova economia, com base eletrônica:

Nessa lógica, os compradores são produtores, [...] ajudando constantemente as companhias eletrônicas a modificar seus produtos e serviços [...] cooperação na inovação e competição em aplicações e serviços parecem ser a divisão do trabalho na nova economia (Castells, 2003: 86). 
As constatações desse estudo tende a sustentar a tese de que, em razão das transformações no sistema de produção global, o emprego assalariado se tornaria menos atraente para indivíduos detentores das capacidades requeridas pela ponta superior da cadeia de produção - atividades não padronizadas que demandam conhecimento técnico, científico, iniciativa e flexibilidade intelectual. No lugar de um emprego, tais indivíduos se esforçariam para - individualmente ou em equipe - descobrir um nicho para a produção de bens ou serviços inovadores (Eliasson, 2006).

Tal mudança seria acompanhada por outra - na esfera da cultura - que se manifesta na subjetividade dos atores, ou seja, nas suas preferências, nos seus valores e modelos mentais. Essa mudança cultural, ao mesmo tempo em que é produto das transformações econômicas, institucionais e tecnológicas é, também, uma força que modela essas últimas, uma vez que oferece recursos cognitivos que estruturam o modo como os atores respondem às oportunidades e constrangimentos presentes no contexto.

O custo para o empreendedor é absorver, isoladamente, as flutuações cíclicas da economia e do mercado, enquanto anteriormente esse era um problema da empresa.

As abordagens que previam o desaparecimento ou a forte redução da atividade de pequeno ou micro empresário high-tech (correspondendo ao desaparecimento da pequena burguesia), podem ser, talvez, relativizadas. As mudanças socioeconômicas e tecnológicas parecem estar contribuindo para a emergência de uma nova realidade em que a atividade de pequeno ou micro empresário aparece em segmentos privilegiados da força de trabaIho. Na Alemanha, por exemplo, cresce a adesão ao emprego por conta própria, de forma estável, em atividades de alta qualificação (McDaniel, 2006: 797). Parece que a ideia de risco e recompensas passou a fazer parte de modelos mentais de certos segmentos da força de trabalho.

Todavia, conclusões mais definitivas em torno dessa questão exigem mais pesquisas. Nesse sentido, estudos sobre o setor intensivo em conhecimento merecem ser ampliados para que se possa continuar observando como evoluem as tendências que ora se evidenciam.

Abstract: The article is concerned with discussing high tech entrepreneurship, which has grown in Brazil, fostered by the advancement of the information and communication technologies and by government actions, 
as illustrated by the Productive Development Policy, from May, 2008, which sets a target of 10 percent growth, for exporting micro and small enterprises, until 2010. The study was based on a multi-dimensional approach underlying the importance of the economic, institutional, cultural and cognitive factors and the interrelationship between the objective and subjective, the macro and micro levels. The empirical data were obtained through interviews with entrepreneurs whose firms are part of technological incubators, located within three university campi, in Rio Grande do Sul, Brazil.

The findings tend to support the hypothesis that a "cultural change "may be taking place among high tech professionals whose skills are highly demanded by the labor market, considering that their behavior, values and objectives differ from what would be expected - to get a stable, well paid job in a large corporation, private or state owned, as well as to embrace economic, individualistic values, as the exercise of power.

\section{Referências}

Abes - Associação Brasileira das Empresas de Software. Disponível na Internet: http:/ /www.abes.org.gov, consultado em 04.08.2009.

AldRICH, H. E. (1995) "Entrepreneurship", in Smelser, N. J. \& Swedberg, R. (eds), The handbook of economic sociology. Princeton: Princeton University Press.

_-_ . (2005) "Entrepreneurship", in Smelser, N. J. \& Swedberg, R. (eds), The handbook of economic sociology, 2. ed.. New Jersey: Princeton University Press.

Ariffin, N. \& Figueiredo, P. (2006) "Globalisation of innovative capabilities: Evidence from local and foreign firms in the electronics industry in Malaysia and Brazil". Science Technology \& Society, Vol. 11, n. 1.

Arora, A \& Gambardella, A. "The globalization of the software industry: Perspectives and opportunities for developed and developing countries", National Bureau of Economic Research, 2004. Disponível na internet: http:/ /www.nber.org/papers/w10538.pdf. Consultado em 20.03.2009.

Artopoulos, A. \& Méndez, M. (2007) "Tics y desarrollo: Conocimiento y cultura", in Finquelievich, S. (coord), La innovación ya no es que era: Impactos metatecnológicos en las areas metropolitanas. Buenos Aires: Editorial Dunken. 
Brasscom - Associação Brasileira de Empresas de Tecnologia da Informação e Comunicação. Índice Brasil para a Convergência Digital, 4. Ed., São Paulo, Brasscom, 2008. Disponível na internet: http://www.brasscom.org.br/. Consultado em 28.04.2009.

Denzau, A. T. \& North, D. C. (1994) "Shared mental models: Ideologies and institutions". Kyklos - International Review for Social Sciences, Vol. 47, n. 1.

CASTELls, M. (2003) A galáxia da Internet: Reflexões sobre a Internet, os negócios e a sociedade. Rio de Janeiro: Jorge Zahar.

Eesley, C. E. (2008) "Who jumps into the sea and when? Entrepreneurship and policy change in China". Paper presented at the SASE Congress, electronic copy.

EliAsSON, G. (2006) "From employment to entrepreneurship: Shifting perspectives in europeand the US on knowledge creation and labour market competition", Journal of Industrial Relations. Londres: Sage, Vol. 48, n. 5.

Figueiredo, P. N. (2006) “Capacidade tecnológica e Inovação em organizações de serviços intensivos em conhecimento: Evidências de institutos de pesquisa em tecnologias da informação e da comunicação (TICs) no Brasil". Revista Brasileira de Inovação, Vol. 5, n. 2.

Finquelievich, S. (coord). (2007) La innovación ya no es que era: Impactos metatecnológicos en las areas metropolitanas. Buenos Aires: Editorial Dunken.

Friedman, T. L. (2006) The world is flat: The globalized world in the twentyfirst century. Londres: Penguins Books.

Folha Online. "Produção científica cresce 56\% no Brasil (2009)", Rio de Janeiro, Folha de São Paulo, disponível em http://www1.folha.uol.com.br/foIha/ciencia/ult306u561181.shtml, consultado em 07.05.2009.

Hualde, A. \& Michel, J. (2008) “Mercados de trabalho nos setores de tecnologia da informação e comunicação no México. Dos call centers à produção de software em pequenas empresas". Tijuana, México, mimeo.

InGRAM, P. \& CLAY, K. (2008) "The choice-within-constraints new institutionalism and implications for sociology". Annual Review of Sociology, Vol. 26. 
INOVAR e investir para sustentar o crescimento. Disponível na Internet: http:/ /www.desenvolvimento.gov.br/pdp/arquivos/destswf1224095287.ppt\#461, 1 , consultado em 17.08.2009.

UndVALL, B. A. (2005) "National Innovation Systems - Analytical concept and development tool", paper presented at the DRUID Tenth Anniversary Summer Conference on Dynamics of Industry and Innovation: Organizations, Networks and Systems, Copenhagen.

MCT - Ministério de CiênCia e Tecnologia. Brasil: Média dos anos de estudo da população em idade ativa - PIA (10 anos ou mais de idade), total, por regiões e unidades da federação 1992 - 2007, Brasília, MCT, 2009, disponível em http://www.mct.gov.br/index.php/content/view/8480.html, consultado em 30.03.2009.

- - . Lei n. 8.248, de 23.10.1991. Brasília, MCT, disponível em http:// www.mct.gov.br/index.php/content/view/6093.html, consultado em 30.03.2009.

McDaniel, S. A. (2006) "Self-employment how individual choices interact with market economies". International Sociology Review of Books, Vol. 21.

MoRAIs, J. M. de. (2008) "Uma avaliação de programas de apoio financeiro à inovação tecnológica com base nos fundos setoriais e na lei de inovação", in De Negri, J. A. \& Kubota, L. C. (orgs), Políticas de incentivo à inovação tecnológica no Brasil. Brasília: Ipea.

NefF, G., Wissinger, E. \& Zukin, S. (2001) “Entrepreneurial labor among cultural producers: 'Cool' jobs in 'hot' industries", Social Semiotics, Vol. 15 n. 3, 2005. North, D. C. "Economic performance through time", in Brinton, M. C. \& Nee, V. (eds), The new institutionalism in sociology. Stanford: Stanford University Press.

- - - (2007) Institutions, institutional change and economic performan$c e, 27$. ed. Nova York. Cambridge University Press.

OCDE - Organisation for Economic Co-operation and Development. (2009) Oslo Manual: Guidelines for collecting and interpreting technological innovation data, OCDE, disponível em http://www.oecd.org/dataoecd/35/61/2367580.pdf , consultado em 31.03.2009. 
Pinheiro, A. C. \& Giambiagi, F. (2006) Rompendo o marasmo. A retomada do desenvolvimento no Brasil. Rio de Janeiro: Elsevier.

Protec - Pró-Inovação Tecnológica na Indústria, Os desafios da inovação e a gestão das empresas. Protec, 2007, disponível em http://www.protec.org.br/ noticias.asp?cod=678, consultado em 20.04.2009.

Salerno, M. S. (2004) "A política industrial, tecnológica e de comércio exterior do governo federal", Parcerias Estratégicas, n. 19. Brasília: Centro de Gestão e Estudos Estratégicos (CGEE ).

Swedberg, R. (2004) Entrepreneurship: The social science view. Nova Délhi: Oxford India Paperbacks.

Thornton, P. H. (1999) "The sociology of entrepreneurship". Annual Review of Sociology, Vol. 25.

Tremblay, D.-G. (2008) "Serviços intensivos em conhecimento e desenvolvimento de conhecimento coletivo no setor de multimídia em Montreal". Montreal, mimeo.

Vedovello, C.; PugA, F. P. \& Felix, M. (2001) “Criação de infraestruturas tecnológicas: A experiência brasileira de incubadoras de empresas". Revista do $B N D E S$, Vol. 8. 